\title{
Using AHP to evaluate the critical factors on management of Indonesian restaurant
}

\author{
Ghina Anggraeni ${ }^{1}$, Chun-Nan Lin ${ }^{*}$, and Siti Azizah ${ }^{3}$ \\ ${ }^{1}$ Student of Join Degree Program, University of Brawijaya, Indonesia \\ ${ }^{1}$ International Master's Degree Program in Agribusiness Management National Pingtung Uni- \\ versity of Science and Technology, Taiwan \\ ${ }^{2}$ Corresponding author and Assistant Professor, Department of Agribusiness Management Na- \\ tional Pingtung University of Science and Technology, Taiwan \\ ${ }^{3}$ Associate Professor Animal Science of Faculty, University of Brawijaya, Indonesia
}

Submitted: 23 June 2019, Accepted: 26 July 2019

\begin{abstract}
The restaurant is serving cuisines and beverages generally at high prices with a high level of service. The main objective of this research is to know evaluation of the critical factors on management of Indonesian restaurant. Qualitative methodologies were applied using survey data with questionnaires and interviews with restaurant proprietor and employees. The Analytic Hierarchy Process (AHP) used in this study various questions that help respond to restaurant management decision making. The results of the survey show the most important of critical factors on management of restaurant of Indonesia is the safety and cleanliness of beverages, added value experience of devour, technology, and building strategic alliances. To sum up, the most important of crucial factors on the management of restaurant Indonesia is consumer demand in the safety model management of cleanliness in cuisine. It also external and internal management influence added value in devouring and technology. The model of the management partner is strategic alliances of building.
\end{abstract}

Keywords: AHP; Indonesian restaurant; management

"Corresponding Author: ghinaanggraeni24@ gmail.com 


\section{INTRODUCTION}

The restaurant is serving cuisines and beverages generally at high prices with a high level of service. From the historical side, the restaurant initially came from restaurants with regular services, until then, the chefs started their own businesses (Cousins, Foskett, and Gillespie, 2002). Restaurant definition is different from popular catering (such as: cafes, steak houses, coffee shops) (Rachmawati, 2011).

By following with the hierarchy of needs, one must meet physiological needs, namely food, water, air, and shelter. Everyone needs food for personal needs before switching to higher demands. In a fastpaced and prosperous society, eating in restaurants is also an important social and business event. Many restaurants offer. Because the number of restaurants has started a lot, so the business becomes more competitive (Widiawati, Indrawati, and Trisnawati, 2018).

Consumers play an essential role in the restaurant industry. Without consumers, the restaurant business cannot survive in the industry. Consumer behavior also gradually change mainly due to rising income levels, a strong economy, changing lifestyle, and customer habits (Umar, 2001). Consumers become more selective and have much consideration in making decisions to choose a place to eat. Consumers set many criteria before they make choices. In terms of the criteria considered necessary when buying food. The highest importance is attributed to the following seven tests: price, taste, nutritional value, raw material and country of origin, Regarding trusted traders, labels and certification bodies (Krystallis and Chryssohoidis, 2005). While demand for Restaurant continues to increase, the restaurant industry is one of the fastest-growing service industries in Taiwan. With the growing competitiveness in industrial restaurants and the similarity of products or services offered by restaurants, it becomes essential for res- taurants that identify the factors that determine the basis that customers choose among restaurants.

Marketing management is an effort to implement, implement which regulates activities, directs, coordinates and overcomes or controls marketing activities in an organization to achieve valid and productive organizational goals. In marketing management, do the analysis carried out to find out the market and its marketing environment, those great opportunities can be obtained to seize the market and increase the significant needs that must be approved (Agustina, 2011).

AHP can be used to determine alternative strategies that have high priority and play a role in influencing results in the hierarchical system (Syukron, 2014). From several alternatives, priority strategies must be determined to be used, a method is needed to solve the problem, one way that can be used is AHP.

\section{LITERATURE REVIEW}

Multicriteria decision-making method for determining location. The criteria set for the Taipei case are explained even though the multicriteria decision-making approach also has a general application. AHP has ive sections and 11 conditions used to develop a location evaluation hierarchy in a restaurant. There are several alternative locations for Pao-San restaurants (Takarazima Japanese Siki Kisegi) in Taipei were evaluated. (Tzeng et al., 2002).

The purpose of this study is to determine the type of restaurant that is preferred for Indonesian food in Kaohsiung. In the Kaohsiung area there are several types of restaurants; fancy restaurants and fast food restaurants. Restaurants have seven ways of comparison: speed of service, alternative menus, quality of food, quality of service, price, the atmosphere of the environment and social environment. AHP procedures apply to individual or group decision making. A compromise decision from an indi- 
vidual's judgment can be calculated. Data were collected by questionnaire and then interest vectors were calculated. Finally, the compromise decision is determined by taking the geometric mean vector of interest (Kilinc et al., 2013).

\section{METHOD}

\section{Data Analysis}

The research structure to describe the conceptual basis of the research and then sets up the questionnaire of the study. Finally, this chapter introduces the research method to discuss the research results. Establishment of Restaurant Management Model: A Case Study of Indonesian Restaurant is influenced for A. Consumer Demand, B. Value Proposition, C. External Influences, D. Internal Influences, and E. Partner.

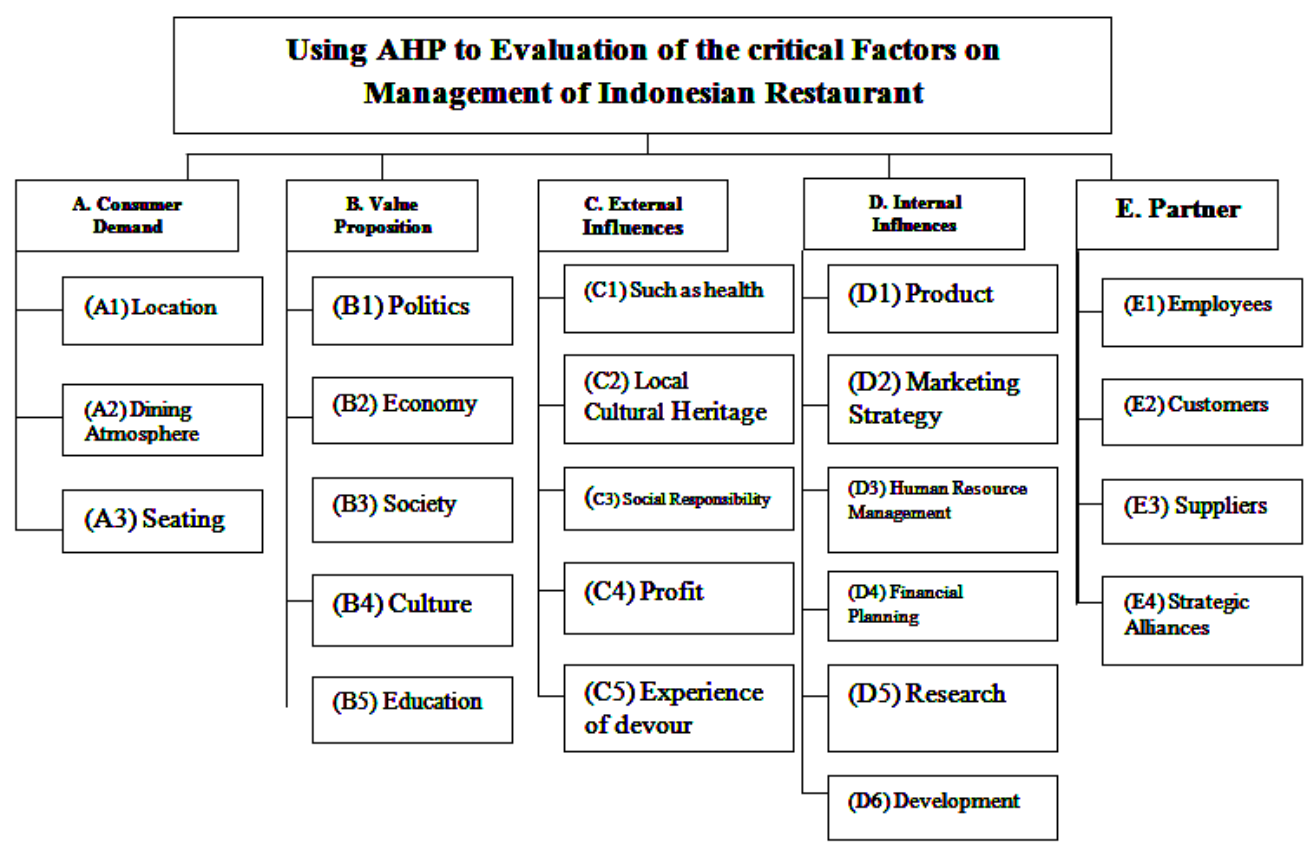

Figure 1. Research structure

Source: Compiled by this study

\section{The Case Study}

The study was conducted purposively at Restaurant in Kaohsiung city, Taiwan. The selection of the research location was made intentionally, with the consideration that. The restaurant was a new restaurant that was established in. Currently, it is still in the early stage in its product lifecycle with monthly sales rates fluctuating. Thus the right marketing strategy is needed in achieving company goals.

\section{Types and Data Sources}

The data collected includes primary data and secondary data, both qualitative and quantitative. Primary data will be obtained by conducting field observations, interviews and questionnaires to the restaurant management. Secondary data will be obtained from literature and literature, books that are relevant to this research, from Restaurant, and other textbooks.

The object of research in this study was the Restaurant of Indonesia's restaurant in Kaohsiung. The number of respondents was 25 people. All of the respondents were collected by an interview from the owner, staff, manager, and restaurant service.

\section{AHP}

This study chose to use the AHP method is an attempt to capture the problems 
found, and the criteria for the answers needed. Then it is simplified in solving these problems to the most straightforward aspects. The AHP method allows to use intuition instruments as the primary input, but the intuition used is coming from decision makers who are sufficiently informed and understand the problem at hand.

The AHP element structure is explained that the objectives are determined through several different criteria. This criterion determines how the quality of achieving the target targets uses one alternative $(A i, \mathrm{i}=1 \ldots \mathrm{k}) . A i$ are various choices, choices or alternatives that can be used to achieve the ultimate goal of the plan. These alternative comparisons determined their importance to each other by a pairwise comparison method. The interest ratio is the key to success in producing alterna- tive pairs; a pairwise comparison matrix is obtained (Wind and Saaty, 1980).

The 9-point scale is used where 9 represents the extreme interests of one goal above another, and 1 represents the same interests between the two goals. Through the normalization process, scores are obtained that reflect the relative importance associated with each goal. Data can be weighed and collected to create a composite score for the study population, or to allow comparison between subgroups of respondents.

The intensity of the 9-point scale of relative importance from 1 to 9 to make pairwise comparisons is subjective and divided into numbers that are equally important, important are being, vital, showing extreme interests and interests. The pair number is from the intermediate value between two adjacent ratings (Burrell and Morgan,2017).

Table 1. Relative importance scale in 9-point intensit.

\begin{tabular}{cll}
\hline $\begin{array}{c}\text { The intensity of } \\
\text { relative importance }\end{array}$ & \multicolumn{1}{c}{ Definition } & \multicolumn{1}{c}{ Explanation } \\
\hline 1 & $\begin{array}{l}\text { Equal importance } \\
\text { Moderate importance of } \\
\text { one over another. } \\
\text { Essential or strong im- } \\
\text { portance. } \\
\text { Demonstrated importance. }\end{array}$ & $\begin{array}{l}\text { The same contribution to goal } 1 . \\
\text { Experience and assessment are a bit } \\
\text { more like an activity. } \\
\text { Experience and assessment that sup- } \\
\text { Activities are very preferred, and their } \\
\text { dominance is shown in practice. } \\
\text { The evidence favoring one activity over } \\
\text { another is of the highest possible order } \\
\text { of affirmation. } \\
\text { Extreme importance. }\end{array}$ \\
$2,4,6,8$ & $\begin{array}{l}\text { Intermediate values a compromise is needed. } \\
\text { tween the two adjacent } \\
\text { judgments }\end{array}$ & \\
\hline
\end{tabular}

Source: Chen (2006).

\section{Implementation of the AHP}

AHP is implemented in three steps: 1). Calculating vectors. 2). Calculate the score matrix. 3). Rate it.

Starting from the top of the hierarchy to descending, comparisons at different levels are reduced to a number of quadratic A (aij) nxn matrices such as the following:

$$
\begin{aligned}
& \left(\begin{array}{llll}
a_{11} & a_{12} & \cdots & a_{1 n}
\end{array}\right)
\end{aligned}
$$

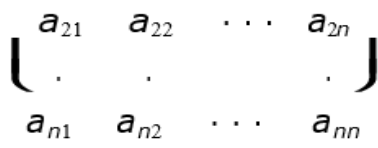


Vector weight, $\mathrm{w}=[\mathrm{w} 1, \mathrm{w} 2, . ., \mathrm{wn}]$, calculated on the Satty eigenvector procedure. Weight calculations are involved in two steps. First, the paired comparison matrix, A (aij) nxn, is normalized by equation (1), and weights are calculated by equation (2).

Normalization:

$$
a_{i j}^{*}=\frac{a_{i j}}{\sum_{i=1}^{n L} a_{i j}}
$$

for all $\mathrm{j}=1,2, \ldots, \mathrm{n}$.

Weight Calculation:

$$
w_{i}=\frac{\sum_{j=1}^{n} a_{i j}^{*}}{n}
$$

Wind and Saaty (1980) shows the relationship between vector, w, and pairwise comparison matrices, A, can be seen in equation (3).

$$
A w=\lambda_{\max } w
$$

The max value $\lambda$ is an important value of AHP and is used as a reference index to find information by calculating the consistency ratio $(\mathrm{CR})$ of vector estimates. The consistency index (CI) for each sequence of $\mathrm{n}$ orders can be obtained from equation (4).

$$
C I=\frac{\lambda_{\max -n}}{n-1}
$$

Then, CR can be calculated using equation (5):

$$
C R=\frac{C I}{R I}
$$

$\mathrm{RI}$ is a random consistency index obtained from a paired comparison matrix to be generated randomly. Table 2 is explained in the RI values from the 1st to the 10th matrix as suggested by Wind and Saaty (1980) If CR $<0.1$ that the ratio is acceptable. However, if $\mathrm{CR}>0.1$, the ratio values indicate that the assessment is inconsistent. In such cases, one must reconsider the original values in the A pair comparison matrix.

Table 2. Random inconsistency indices (RI) for $\mathrm{N}=10$.

\begin{tabular}{ccccccccccc}
\hline $\mathrm{N}$ & 1 & 2 & 3 & 4 & 5 & 6 & 7 & 8 & 9 & 10 \\
\hline $\mathrm{RI}$ & 0.00 & 0.00 & 0.58 & 0.9 & 1.12 & 1.24 & 1.32 & 1.41 & 1.46 & 1.49
\end{tabular}

Source: Wind and Saaty (1980).

The decision-maker starts processing the comparison of criteria, sub-criteria, and alternative pairs using a 9-point scale. Assessment is given, consistency of assessment on each matrix seen. If the consistency ratio is less than or equal to 0.1 , the rating is accepted. However, if the value of the consistency ratio is greater than 0.1 the decision-maker is then asked to modify their judgment. After the modified process is carried out and the consistency ratio is less than 0.1 , the matrix is normalized.

\section{RESULT}

This chapter uses the Analytic Hierarchy Process (AHP) to test the questionnaire results using the computer program Power
Choice V2.5. First, DELPHI tests are used to test the obtained a good questionnaire. Then the AHP is tested concerning the essential characteristics of factor in the operation of the Indonesian cuisine gourmet restaurant.

\section{Identification of Restaurant Indonesia}

Indonesian restaurants are increasingly wandering. The proof is that more and more restaurants offer archipelago menus in various countries in the world. One of them is in Kaohsiung, Taiwan. Compared to Taipei, Kaohsiung is rarely heard. However, the city is the second largest airport location in Taiwan, namely 
Kaohsiung International Airport and the largest seaport in Taiwan.

\section{DELPHI analysis}

All questions in the questionnaire were analyzed by DELPHI method. These questions are located in the average more than 3 and coefficient of variation less or equal 0.5 , allowing keeping going with AHP analysis. The questionnaire analyzed by DELPHI method all calculations have passed.

\section{AHP analysis}

Table 3 provides the most relevant results for respondents with local and overall weights. The importance starts with A. Consumer Demand, B. Value Proposition, C. External Influences, D. Internal Influences, and E. Partner. This explains that respondents discussed the importance of partners in the company. The next consideration of the respondent criteria is internal influences and value proposition. The results of the study show that factor partners can be essential consideration for restaurants. That the owner has a good relationship with the partner for the interests of the restaurant.

Table 3. General Criteria analysis

\begin{tabular}{lcc}
\multicolumn{1}{c}{ Criteria } & Local weight & Priorities \\
\hline 1. Consumer Demand. & 0.052 & 5 \\
2. Value Proposition. & 0.143 & 3 \\
3. External Influences. & 0.133 & 4 \\
4. Internal Influences. & 0.195 & 2 \\
5. Partner. & 0.475 & 1 \\
\hline
\end{tabular}

Note : $1 . \lambda \max =5.08825$

2. C.I. $=(5.08825-5) /(5-1)=0.023$

3. C.R. $=0.023 / 1.12=0.020$

Source: Compiled by this study.

$\mathrm{CI}$ is a calculation from the previous step with a value of 0.023 . Viewed from $n$ $=5, \mathrm{RI}=1.12$. Use of these values for $\mathrm{CI}$ and RI, C.R $=0.0 .23 / 1.12=0.020$. The calculation of the analysis obtained a value of 0.020 , in the proportion of CR inconsistencies below 0.10 , with the proportion of CR inconsistencies less than 0.10 , so that it can accept that this assessment has been fulfilled in order to continue decision making using the AHP process.

\section{Consumer Demand Validation}

Table 4 shows the local and overall weights on consumer demand criteria with each factor. The requirements for the highest to lowest consumer demand are: A7. The safety and cleanliness of food, A6. Restaurant service, A5. Parking, A2. Taste, A3. The atmosphere of the dining environment (music and decoration), A4. Tra- ditional Indonesia cuisine, and A1. Location. This restaurant has a variety of facilities offered. The site where the restaurant is crucial, A1. It is important to eat traditional Indonesian cuisine, A4. The atmosphere of the dining environment (music and decoration) is important, A3. It is vital that the dish is delicious, A2. Whether a good restaurant for parking is the importance, A5. Restaurant-wise service is the importance, and A6. The safety and cleanliness of food provided by restaurants importance, A7. The results show the most important of critical factors on the management of restaurant of Indonesia consumer demand that The safety and cleanliness of food provided by restaurants importance factors can be an important consideration for restaurants. So owner can do many evaluation. 
Table 4. Criteria A. Consumer Demand

\begin{tabular}{|c|c|c|}
\hline Criteria & Local weight & Priorities \\
\hline A1. The location where the restaurant is important. & 0.0021 & 7 \\
\hline A2. It is important that the dish is delicious. & 0.0041 & 4 \\
\hline $\begin{array}{l}\text { A3. The atmosphere of the dining environment (music and } \\
\text { Decoration) is important. }\end{array}$ & 0.0043 & 5 \\
\hline A4. It is important to eat traditional Indonesian cuisine. & 0.0042 & 6 \\
\hline A5. Whether a good restaurant for parking is the importance. & 0.0048 & 3 \\
\hline A6. Restaurant-wise service is the importance. & 0.0095 & 2 \\
\hline $\begin{array}{l}\text { A7. The safety and cleanliness of food provided by restaurants } \\
\text { importance. }\end{array}$ & 0.022 & 1 \\
\hline
\end{tabular}

Note: $1 . \lambda \max =7.17257$

2. C.I. $=(7.17257-7) /(7-1)=0.029$

3. C.R. $=0.029 / 1.32=0.022$

Source: Compiled by this study.

The $\mathrm{CI}$ value is $0.029, \mathrm{n}=7, \mathrm{RI}=1.32$. By using these values for CI and RI, it can be calculated that C.R $=0.029 / 1.32=$ 0.022 . The value is 0.022 , with the proportion of $\mathrm{CR}$ inconsistencies below 0.10 , with the proportion of $\mathrm{CR}$ inconsistencies below 0.10 , so that it can be accepted that this assessment has been fulfilled so that we can continue making decisions - making the process using AHP.

\section{Value Proposition Validation}

Table 5 shows the local and overall weights on consumer demand criteria with each factor. The criteria for the highest to lowest consumer demand are: B7. Education activities, B6 Social network, B5 Folk culture, B4 Religion, B2 Price, B3 Nationality, and B1 Government policies. This restaurant has a variety of facilities offered. B7. The overall level of education in the community is important for the service of the Indonesian Restaurant. B6. An important social network for Indonesian Restaurant operations. B5. Folk culture is important for Indonesian Restaurant operations. B4. Important religious beliefs for the operation of the Indonesian Restaurant. B2. Important in the sales price of the Restaurant. B3. National ability to buy is important for the Indonesian Restaurant operation. B1. Government policies are important for Indonesian Restaurant operations. The results show the most important of critical factors on the management of restaurant Indonesia of a value proposition that value proposition can be customers are interested in buying because restaurants provide halal food and because there is a sense of nationality. 
Table 5. Criteria B. Value Proposition

\begin{tabular}{lcc}
\hline Criteria & Local weight & Priorities \\
\hline $\begin{array}{l}\text { B1. Government policies are important for Indonesian Restau- } \\
\text { rant operations. }\end{array}$ & 0.0054 & 7 \\
$\begin{array}{l}\text { B2. Important in the sales price of the Restaurant. } \\
\text { B3. National ability to buy is important for the Indonesian Res- } \\
\text { taurant operation. }\end{array}$ & 0.0119 & 5 \\
$\begin{array}{l}\text { B4. Important religious beliefs for the operation of the Indone- } \\
\quad \text { sian Restaurant. }\end{array}$ & 0.0117 & 6 \\
$\begin{array}{l}\text { B5. Folk culture is important for Indonesian Restaurant opera- } \\
\quad \text { tions. }\end{array}$ & 0.014 & 4 \\
$\begin{array}{l}\text { B6. An important social network for Indonesian Restaurant op- } \\
\text { erations. }\end{array}$ & 0.024 & 2 \\
$\begin{array}{l}\text { B7. The overall level of education in the community is im- } \\
\text { portant for the operation of the Indonesian Restaurant. }\end{array}$ & 0.064 & 1 \\
\hline
\end{tabular}

Note: $1 . \lambda \max =7.13905 \quad$ 2. C.I. $=(7.13905-7) /(7-1)=0.024 \quad$ 3. C.R. $=0.024 / 1.32=0.018$

Source: Compiled by this study.

$\mathrm{n}=7, \mathrm{RI}=1.32$. By using these values

for $\mathrm{CI}$ and RI, it can be calculated that C.R $=0.024 / 1.32=0.018$. The calculation results of the analysis obtained a value of 0.018 , with the proportion of CR inconsistencies less than 0.10 , with a proportion of inconsistency CR less than 0.10, which means we can accept that this assessment has been fulfilled so that we can continue making decisions - making the process using AHP.

\section{External Influences Validation}

Table 6 shows the local and overall weights on consumer demand criteria with each factor. The criteria for the highest to lowest consumer demand are: C6. Valueadded experience of eat. C5. Profit. C4. Social. C3. History Restaurant. C2. Culture. C1. Healthy food. The results show the most important of critical factors on management of restaurant Indonesia of external influences that the addition of products in restaurants will attract consumers to buy restaurants and profits for restaurants are very influential in selling Restaurant.

Table 6. Criteria C. External Influences

\begin{tabular}{lcc}
\hline Criteria & Local weight & Priorities \\
\hline $\begin{array}{l}\text { C1. It is important to provide healthy food in Indonesian Res- } \\
\text { taurants. }\end{array}$ & 0.006 & 6 \\
$\begin{array}{l}\text { C2. It is important that Indonesian Restaurants are rich in local } \\
\text { culture. }\end{array}$ & 0.011 & 5 \\
$\begin{array}{l}\text { C3. It is important to introduce story products in Indonesian } \\
\quad \text { Restaurants. }\end{array}$ & 0.012 & 4 \\
$\begin{array}{l}\text { C4. Food restaurants are important for social responsibility. } \\
\text { C5. It is important to get a reasonable profit from Indonesian } \\
\quad \text { Restaurants. }\end{array}$ & 0.016 & 0.022 \\
$\begin{array}{l}\text { C6. It is important that Indonesian Restaurants offer a value- } \\
\text { added experience of eat. }\end{array}$ & 0.062 & 2 \\
\hline
\end{tabular}

Note: $1 . \lambda \max =6.14092 \quad$ 2. C.I. $=(6.14092-6) /(6-1)=0.029 \quad$ 3. C.R. $=0.029 / 1.24=0.023$

Source: Compiled by this study. 
The CI value is 0.029. $\mathrm{n}=6, \mathrm{RI}=1.24$. By using these values for CI and RI, it can be calculated that C.R $=0.029 / 1.24=$ 0.023 . The calculation results of the analysis obtained a value of 0.023 , with the proportion of $\mathrm{CR}$ inconsistencies less than 0.10 , with the proportion of CR inconsistencies less than 0.10 , which means we can accept that this assessment has been fulfilled so that we can continue the decisionmaking process using AHP.

\section{Internal Influences Validation}

Table 7 shows the local and overall weights on consumer demand criteria with each factor. The criteria for the highest to lowest consumer demand are: D6. Technology. D5. Performance of employees. D4. Financial planning, control, and auditing. D3. Education and training. D2. Marketing promotion. D1. Product differentiation. The results show the most important of critical factors on management of restaurant Indonesia of internal influences that the addition of technology in processing Restaurant will facilitate the work of employees and the assessment of employee work performance is very influential in the performance of employees managing the restaurant properly.

Table 7. Criteria D. Internal Influences

\begin{tabular}{lcc}
\hline Criteria & Local weight & Priorities \\
\hline $\begin{array}{l}\text { D1.Indonesian Restaurants emphasize the importance of } \\
\text { product differentiation strategies. }\end{array}$ & 0.010 & 6 \\
$\begin{array}{l}\text { D2. Marketing promotion activities in Indonesian Restau- } \\
\text { rants are important. }\end{array}$ & 0.022 & 5 \\
$\begin{array}{l}\text { D3. Education and training of Indonesian Restaurant staff } \\
\quad \text { are important. }\end{array}$ & 0.027 & 4 \\
$\begin{array}{l}\text { D4. Financial planning, control, and auditing of Indonesian } \\
\quad \text { Restaurants are important. }\end{array}$ & 0.033 \\
$\begin{array}{l}\text { D5. Knowing the performance of employees in the restau- } \\
\quad \text { rants. }\end{array}$ & 0.035 & 2 \\
$\begin{array}{l}\text { D6. Restaurants Restaurant use technology to manage their } \\
\text { operations. }\end{array}$ & 0.065 & 1 \\
\hline
\end{tabular}

Note: $1 . \lambda \max =6.145792$. C.I. $=(6.14579-6) /(6-1)=0.030 \quad$ 3. C.R. $=0.030 / 1.24=0.024$

Source: Compiled by this study.

$\mathrm{n}=6, \mathrm{RI}=1.24$. By using these values for CI and RI, it can be calculated that C.R $=0.030 / 1.24=0.024$. The calculation results of the analysis obtained a value of 0.024 , with an inconsistency proportion of CR less than 0.10 , with a proportion of inconsistency CR less than 0.10 , which means we can accept that this has been fulfilled so that we can make decisions - make the process using AHP.

\section{Partner Validation}

Table 8 shows the local and overall weights on consumer demand criteria with each factor. The criteria for the highest to lowest consumer demand are: E5. Building strategic alliances. E2. Job satisfaction. E3. The strength of bargaining with suppliers. E4. Partner structure. E1. Relationship customer. The results show the most important of critical factors on management of restaurant Indonesia of partner that Building strategic alliances are very influential in maintaining relationships with restaurant partners and Job satisfaction is very influential to maintain the harmony of the owner and staff. 
Table 8. Criteria E. Partner

\begin{tabular}{|c|c|c|}
\hline Criteria & Local weight & Priorities \\
\hline $\begin{array}{l}\text { E1. Building an important customer relationship management } \\
\text { system to operation a Indonesian Restaurant. }\end{array}$ & 0.037 & 5 \\
\hline $\begin{array}{l}\text { E2. Job satisfaction with employees is important to operation } \\
\text { the Indonesian Restaurant. }\end{array}$ & 0.087 & 2 \\
\hline $\begin{array}{l}\text { E3. The strength of bargaining with suppliers is important for } \\
\text { the Indonesian Restaurant operations. }\end{array}$ & 0.083 & 3 \\
\hline $\begin{array}{l}\text { E4. An important partner structure for the operation of the In- } \\
\text { donesian Restaurant. }\end{array}$ & 0.078 & 4 \\
\hline $\begin{array}{l}\text { E5. Building strategic alliances with various industries are im- } \\
\text { portant to operating the Indonesian Restaurant. }\end{array}$ & 0.188 & 1 \\
\hline
\end{tabular}

$\mathrm{n}=5, \mathrm{RI}=1.12$. Using these values for $\mathrm{CI}$ and RI, it can be calculated that $\mathrm{C} \cdot \mathrm{R}=$ $0.011 / 1.12=0.010$. The calculation results of the analysis obtained a value of 0.010 , with the proportion of CR inconsistencies less than 0.10 , with the proportion of CR inconsistencies less than 0.10 , which means we can accept that this assessment has been fulfilled so we can continue the decision - making the process using AHP.

\section{CONCLUSION}

This study reviews and compiles the literature and relevant material regarding Management Restaurant, starting with Indonesian Restaurant in Kaohsiung, and then reviews the establishment of restaurant management model and multi-criteria decision making with AHP analysis which acts as the theoretical basis in where to build and describe management factors by owners, staff, and managers. in this research. Based on the results of analysis and discussion, it can be concluded as follows:

To sum up, the most important of crucial factors on the management of restaurant Indonesia is consumer demand in the safety model management of cleanliness in cuisine. It also external and internal management influence added value in devouring and technology. The model of the management partner is strategic alliances of building.

\section{REFERENCE}

Agustina, S. (2011). Manajemen pemasaran. In: UB Press.

Burrell, G and Morgan, G. (2017). Sociological paradigms and organisational analysis: Elements of the sociology of corporate life: Routledge.

Chen, C.-F. J. J. o. T. R. (2006). Applying the analytical hierarchy process (AHP) approach to convention site selection. 45(2), 167-174.

Cousins, J., Foskett, D and Gillespie, C. (2002). Food and beverage management: Pearson Education.

Kilinc, C. C., Semiz, M., Katircioglu, E and Unusan, Ç. J. I. J. o. E. P. (2013). Choosing Restaurant for Lunch in Campus Area by the Compromise Decision via AHP. $7(2)$.

Krystallis, A and Chryssohoidis, G. J. B. F. J. (2005). Consumers' willingness to pay for organic food: Factors that affect it and variation per organic product type. 107(5), 320-343.

Rachmawati, R. J. J. K. T. (2011). Peranan bauran pemasaran (marketing mix) terhadap peningkatan penjualan (sebuah kajian terhadap bisnis restoran). 2(2). 
Syukron, A. J. G. I., Yogyakarta. (2014). Pengantar Manajemen Industri.

Tzeng, G.-H., Teng, M.-H., Chen, J.-J and Opricovic, S. (2002). Multicriteria selection for a restaurant location in Taipei. International Journal of Hospitality Management, 21(2), 171-187.

doi:https://doi.org/10.1016/S02784319(02)00005-1

Umar, H. (2001). Strategic management in action: Gramedia Pustaka Utama.
Widiawati, L., Indrawati, $\mathrm{H}$ and Trisnawati, F. J. J. O. M. F. K. d. I. P. U. R. (2018). Strategi Bersaing Usaha Warung Tenda Pecel Lele di Sepanjang Jalan Lintas Timur Kecamatan Pangkalan Kerinci Kabupaten Pelalawan. 5(1), 1-15.

Wind, Y and Saaty, T. L. J. M. s. (1980). Marketing applications of the analytic hierarchy process. 26(7), 641658. 